\title{
Distritos 2.217: um processo de drama com adolescentes
}

\section{Districts 2.217: a process drama with teenagers}

Wellington Menegaz ${ }^{1}$ 


\section{Resumo}

Nesse artigo apresento reflexões do processo de drama Distritos 2.217. Essa prática foi realizada no ano de 2017 pelo subprojeto Teatro do Programa Institucional de Bolsas de Iniciação à Docência PIBID da Universidade Federal de Uberlândia, com estudantes dos nonos anos do ensino fundamental de uma Escola Municipal de Uberlândia (MG). Partindo da premissa que é possível e necessário trabalhar política, teatro e sociedade em processos artísticos e pedagógicos com adolescentes, a pergunta que permeia essa escrita é: como desenvolver uma prática artística que destaque o olhar dos adolescentes para questões políticas que os atravessam?

Palavras-chave: Drama; ensino; adolescentes; política; processo

\section{Abstract}

In this article I bring some of my thoughts about the process drama Distritos 2.217. This practice took place in 2017 through a Theater subproject in the Institutional Program for Teaching Initiation Scholarships PIBID at the Federal University of Uberlândia. It involved students from the ninth grade from elementary public schools in Uberlândia (MG). Assuming that it is possible and necessary to bring together politics, theater and society in artistic and pedagogical processes with teenagers, the question which presents itself in this writing is: how to develop an artistic practice which would bring the teenagers' perspective of the political issues around them?

Keywords: Drama; teaching; teenagers; politics; process 
Falar de ensino de teatro em escolas formais é um ato de resistência. Resistir a desvalorização da educação, tanto básica, quanto superior. Resistir a desvalorização do professor e professora que constantemente são julgados/as pela mídia e pela sociedade em geral. Escrever sobre o cotidiano da sala de aula é revelar vozes silenciadas, que não estão nos "holofotes". Vozes de professores/professoras que ensinam e partilham o fazer teatral, os/as quais, muitas vezes são duplamente marginalizados/ as, por serem educadores e artistas. No nosso país ainda há municípios que insistem em não reconhecer o teatro e outras modalidades artísticas como campos de conhecimento na disciplina Arte da educação básica.

Importante que artistas docentes visibilizem seus fazeres para fora da escola, através do compartilhamento de suas práticas/pesquisas pedagógicas em congressos, encontros, artigos etc., com o intuito de reverberar poéticas e saberes presentes no ofício de ser e permanecer docente. Considero a escrita uma das formas de democratizar conhecimentos, de visibilizar o existir, de partilhar conquistas cotidianas que são criadas no "chão da escola", através do transitar de saberes entre a sala de aula e a sociedade, da circulação de jogos, cenas, improvisações, processos de Drama, que diariamente são desenvolvidos com crianças, adolescentes e jovens em diversas escolas de educação básica espalhadas pelo Brasil.

Ao observar as comunicações apresentadas nos Encontros Nacionais do Grupo de Trabalho Pedagogia das Artes Cênicas da Associação Brasileira de Pesquisa e Pós-graduação em Artes Cênicas (ABRACE), percebo que nos últimos anos ocorreu aumento das pesquisas de práticas relacionadas à educação básica. Considero que isso se deu através da implementação de duas ações: Mestrado Profissional em Artes (Prof-Artes); e o Programa Institucional de Bolsa de Iniciação à Docência (PIBID). Ambas trouxeram investigações que tem como foco o "chão da escola" e suas reverberações a partir de trabalhos realizados em aulas de Arte. Nesse artigo apresento um relato de experiência, recortes de um trabalho realizado em uma dessas ações, no caso o PIBID.

A experiência partilhada foi um processo de Drama com adolescentes, que teve como meta a vivência de uma prática teatral e a investigação de temas relacionados a política e sociedade, elencados pelos próprios adolescentes que participaram do processo. Essa prática foi realizada pelo subprojeto Teatro PIBID² da Universidade Federal de Uberlândia UFU no ano de 2.017, com estudantes dos nonos anos do ensino fundamental da Escola Municipal Sérgio de Oliveira Marquês, localizada no bairro Pacaembu, do município de Uberlândia (MG). Nessa instituição tínhamos seis bolsistas de iniciação à docência, a professora supervisora Neibe Leane da Silva e eu, enquanto coordenador do subprojeto. Partindo da premissa que é possível e necessário trabalhar política, teatro e sociedade em processos artísticos e pedagógicos com adolescentes, no intuito de serem agentes críticos e protagonistas de sua história, e da história que os cercam, a pergunta que permeou essa escrita foi: como desenvolver

2 Com início no ano de 2.011, o subprojeto Teatro UFU contou ao longo de sua trajetória com a parceria de uma ou duas escolas de educação básica por ano. Minha trajetória começa a coincidir com o subprojeto no ano de 2.014, momento em que me tornei coordenador do subprojeto Teatro PIBID, permanecendo nessa função por quatro anos. No ano de 2.017 o subprojeto Teatro PIBID UFU contava com duas escolas parceiras, dois professores supervisores e doze bolsistas de iniciação à docência. 
uma prática artística que destaque o olhar dos adolescentes para questões políticas que os atravessam?

\section{Primeiras inquietações}

No ano de 2.017 o subprojeto Teatro PIBID UFU desenvolveu diversas ações na Escola Municipal Sérgio de Oliveira Marquês, com o intuito de levar o fazer teatral para adolescentes, através de jogos teatrais, brincadeiras tradicionais e improvisações. Eram ações ${ }^{3}$ pensadas por toda equipe, em momentos de reuniões semanais.

A partir dessas experiências que perpassaram o primeiro semestre, alguns dos bolsistas do subprojeto queriam desenvolver práticas teatrais que tivessem conexões com questões emergenciais que atravessavam o cotidiano dos adolescentes e temáticas políticas que inquietavam os jovens bolsistas do PIBID Teatro. Vale ressaltar, que no ano anterior havíamos vivenciado uma greve das Universidades Federais e o movimento de Ocupação das escolas estaduais em Minas Gerais pelos secundaristas, com pautas relacionadas a melhoria da educação pública no Brasil. Esses movimentos e suas pautas em defesa de uma educação de qualidade, reverberaram em nossos encontros semanais ao longo do ano de 2.017. Sentíamos a necessidade de criar em nossas ações um campo lúdico de debate e fazer teatral.

Paralelo a essas inquietações havia um desejo meu, já compartilhado com os bolsistas há algum tempo, de desenvolver um processo de Drama com os estudantes dos nonos anos do ensino fundamental. E aqui vale destacar que me refiro ao Drama como possibilidade de ensino, um método estruturado a partir dos estudos que Beatriz Ângela Vieira Cabral trouxe para o Brasil no final da década de 90. Dentre as diversas possibilidades de análise do Drama, o considero enquanto "uma investigação teatral de um pré-texto, por meio da criação de contexto ficcional, definição de papéis (roles) para os estudantes e professor bem como atividades teatrais a serem exploradas e investigadas" (Paula, 2016, p. 18).

Então, decidimos unir nossos desejos, ou seja, elaborar e desenvolver um Drama que possibilitasse explorar o olhar dos estudantes para questões que perpassavam a política e sociedade atual. Importante destacar os nomes dos bolsistas que fizeram parte desse processo, uma vez que a elaboração e desenvolvimento do Drama Distritos 2.217 foi uma ação coletiva da equipe do subprojeto Teatro que atuava na escola. São elas e eles: Alisson Guerradr, Ana Vitória Nogueira, Brenda Andrade, Carla Luz, Rafael Roberto, Samuel Gonçalves e Thainá Maria. Por conhecermos as turmas foi possível pensar em um processo que dialogasse com o contexto social e político em que os estudantes estavam inseridos. Porém, com uma escuta sensível para ouvir e respeitar as inquietações trazidas pelos adolescentes através do teatro.

Nosso primeiro passo foi definir o pré-texto e o contexto ficcional. Em relação ao pré-texto, vale ressaltar que ele "é o roteiro, história ou texto que fornecerá o ponto de partida para iniciar o processo dramático, e que irá funcionar como pano de fundo para orientar a seleção e identificação das atividades e situações exploradas"

3 Algumas foram desenvolvidas pela professora supervisora e acompanhadas pelos bolsistas, e outras pelos bolsistas, com a orientação e supervisão tanto da professora, quanto minha. 
(Cabral, 2006, p. 15). Optamos na investigação de temas sociais e políticos enquanto pré-texto, que inquietavam os adolescentes naquele ano. Não definimos quais seriam esses temas, pois a intenção era que eles surgissem ao longo do Drama.

O próximo passo foi definir o contexto de ficção, uma vez que buscávamos que os adolescentes pudessem emitir seus pontos de vista e posicionamentos a respeito de questões sociais e políticas, sem o receio da crítica de outros colegas, ou mesmo dos coordenadores da ação. Para isso, era fundamental que delimitássemos um contexto ficcional distante da nossa realidade, para que através desse distanciamento, os estudantes sentissem confortáveis para se expressarem. Sobre o contexto de ficção no Drama compartilho da reflexão de Simões (2013, p. 67):

O contexto ficcional permite a exploração de temas e assuntos relativos a um outro lugar, diferente de nosso cotidiano. A delimitação do contexto propicia que os participantes sejam transportados metaforicamente para esse outro lugar, onde as investigações acontecem. O tema a ser explorado é desdobrado, ao longo do processo, em situações e circunstâncias dramáticas que compõem os episódios, levando à construção de uma narrativa teatral.

Após diversas ideias, delimitamos que a ficção aconteceria em um futuro distante, no ano de 2.217. Nos inspiramos em alguns filmes e séries trazidos pelos bolsistas, que passavam no futuro, como a série $3 \%$ e a sequência dos longas metragens de Jogos Vorazes e Divergente. Nos processos de Drama que desenvolvo com adolescentes, busco dialogar com o contexto cultural e/ou artístico dos próprios adolescentes. Através de elementos presentes na internet - redes sociais, séries, filmes, jogos online etc, que servem como inspiração para as atividades, papéis ou enquanto pré-texto. O intuito dessa ação é através de uma cultura cibervirtual, presente no cotidiano dos estudantes, conseguir encontrar pistas para a imersão e participação dos adolescentes nos processos de Drama.

No contexto de ficção que escolhemos a terra havia sido devastada. O motivo dessa devastação começou por volta de aproximadamente 200 anos atrás, ou seja, em 2.017. Apenas algumas pessoas sobreviveram, os moradores dos Distritos. Os quais tinham como missão construir uma nova sociedade. Mas para isso, precisariam revisitar o passado, para que os "erros" de seus ancestrais, que levaram a destruição de quase toda a população da terra, não fossem mais cometidos. Para ajudar esses moradores, principalmente no resgate da memória do passado, apareceram os viajantes do tempo, que conheciam momentos decisivos da história do país. Eram conselheiros, que auxiliariam os moradores na construção de uma nova sociedade, mais justa do que as anteriores. Mas o que seria uma sociedade mais justa? Tínhamos como meta que os participantes trouxessem seus pontos de vista para tal pergunta, sem fecharmos em uma definição, pois o que pode ser considerado como justo para alguns, não é necessariamente justo para outros.

Outro elemento da ficção que criamos, foi a figura de Capitu, uma mulher que viveu na década de trinta (do século $\mathrm{XX}$ ) e lutou contra as desigualdades sociais. Como não encontrou "eco" para que isso acontecesse no seu tempo, criou uma sociedade secreta de viajantes do tempo, que tinha a missão de ajudar pessoas no futuro em momentos críticos da humanidade. Com isso, alguns de seus seguidores viajaram 
rumo ao ano em que a terra já havia sido devastada, pois esse era o momento que consideravam ideal para que os "erros" do passado, que levaram a essa devastação, fossem reparados. No processo essa ficção seria explorada durante alguns encontros, que no Drama denominamos de episódios. Segundo Cabral:

Identificação e delimitação de um contexto de ficção determinam um foco comum de atenção para a criação em grupo, a qual se desenvolve na forma de um processo de investigação cênica - uma sequência de episódios que ocorrem em aulas distintas ao longo do semestre, permitindo que a "voz do aluno" seja ouvida e aspectos significativos que tenham aflorado sejam o ponto de partida do episódio seguinte. Um episódio é, assim, uma situação ou fragmento da criação coletiva em processo, o qual é destacado para uma investigação cênica mais detalhada (Cabral, 2014, p. 105-106, grifos da autora).

Para o desenvolvimento dessa investigação cênica, era preciso definirmos outros aspectos relacionados ao Drama: os papéis e atividades que perpassariam o primeiro episódio. Começamos a pensar sobre quais seriam os papéis assumidos tanto pelos bolsistas, quanto pelos estudantes dos nonos anos. De acordo com Bowell e Heap (2013, p. 12): "A atividade fundamental no drama está em assumir um papel - imaginando que você está andando na pele de outra pessoa e explorando uma situação através dos olhos dessa pessoa"4 . No Drama estudantes e professor(es)/professora(s) assumem papéis que se relacionam diretamente com o contexto ficcional e pré-texto investigado. Vale ressaltar que usamos a nomenclatura professor-personagem (teacher-in-role) para os momentos em que o/a professor(a) assumem um ou mais papéis durante o processo de Drama.

No elaborar da ficção já havíamos pensado que os estudantes dos nonos anos seriam os moradores dos Distritos. Sendo que cada turma seria um Distrito. Porém alguns detalhes precisavam ser delineados, como por exemplo a função deles nessa sociedade. Então definimos que no primeiro e segundo episódio os adolescentes seriam os governantes, ou seja, as pessoas que possuíam o "poder" de tomar algumas decisões. Tínhamos o desejo de que em outras aulas/episódios assumissem os papéis da população que receberiam as decisões tomadas pelos governantes. Importante destacar que no Drama as atividades são criadas após o término do episódio anterior, uma vez que dependerá do retorno obtido nesse encontro para o planejamento do episódio seguinte. Só após o segundo encontro é que decidimos que a mudança nos papéis dos estudantes aconteceria.

Definimos que os papéis dos bolsistas seriam de viajantes do tempo. Criamos dois grupos, o primeiro era dos conselheiros, que tinham como função auxiliar os moradores dos Distritos na construção dos parâmetros que iriam reger essa nova sociedade. Os nomes ${ }^{5}$ dos conselheiros eram códigos, formados por letras e números, uma alusão a filmes de ficção científica: Madame E 26; Dr. L 22; T $22^{6}$. O outro grupo, o dos mensageiros do tempo, entrariam em momentos específicos do pro-

\footnotetext{
4 Tradução minha. Texto original: "The fundamental activity in drama is taking on a role - imagining that you are walking in the shoes of someone else and exploring a situation through that person's eyes" (Bowell; Heap, 2013, p. 12). (Tradução nossa)

5 Cada bolsista escolheu o nome de seu papel.

6 Os bolsistas que vivenciaram esses papéis foram: Carla Luz, Alisson Guerradr e Rafael Roberto, respectivamente.
} 
cesso com o intuito de inserir alguma informação ou auxiliar os conselheiros sempre que necessário, e tinham os seguintes nomes: A 2, Pi e A $7^{7}$. Havia também o papel de Capitu, antes do processo iniciar não havíamos decidido se ela apareceria em algum momento ou se seria apenas mencionada. Porém, após a realização do segundo episódio, decidimos que ela enviaria uma mensagem de vídeo. Queríamos que esse vídeo fosse um elemento surpresa, que causasse impacto no momento da exibição. Para contribuir com essa intenção, convidamos uma bolsista ${ }^{8}$ que os estudantes do nono ano não conheciam, pois fazia parte da equipe de outra escola.

Elaboramos antes do processo começar apenas o primeiro episódio, que teria duração de cinquenta minutos, tempo de uma aula de Arte. As atividades foram pensadas com o intuito de proporcionar espaços de criação para os estudantes, em que seus pontos de vista e posicionamentos fossem ouvidos e assimilados. Após o término do primeiro encontro, nos reunimos e a partir do retorno dos adolescentes é que elaboramos o episódio seguinte, e assim sucessivamente.

Além das atividades que seriam desenvolvidas, nos preocupamos com a escolha dos materiais, figurinos e maquiagens. $O$ objetivo era que as visualidades presentes na atividade pudessem contribuir para imersão dos participantes no processo. Para tanto, era necessário que essa escolha dialogasse com a ficção explorada, que estabelecia um fluxo entre o passado e o futuro. Aponto o cuidado na elaboração dos pergaminhos e da presença de uma máquina de escrever antiga, para dar a ideia de materiais encontrados em uma cápsula do tempo, e o contraste que esses materiais estabeleciam com o figurino e maquiagem dos bolsistas, nos dois primeiros encontros, que remetiam a personagens que poderiam habitar um futuro distante.

No processo Distritos 2.217 foram desenvolvidos três episódios, sendo que cada um aconteceu em uma aula: primeiro episódio - $A$ chegada e Uma nova sociedade; segundo - Identidade do Distrito; terceiro e último - Uma sociedade justa? Esse processo foi realizado com as três turmas dos nonos anos da escola, porém nesse artigo compartilharei o relato da investigação de apenas uma delas.

\section{A chegada}

Para estabelecer o "contrato" com a ficção, uma semana antes do início do processo, anunciamos que na próxima aula começaríamos uma atividade teatral na qual todos seriam personagens, optamos por não utilizar a palavra papéis. Compartilhamos um resumo do contexto ficcional que havíamos criado e revelamos "quem" os estudantes e os bolsistas iriam desenvolver. Com isso, as regras iniciais do jogo estavam claras e os adolescentes foram para suas casas conscientes de que na semana seguinte o processo iniciaria.

O primeiro episódio começou com a entrada na sala de aula de quatro bolsistas, professores-personagens. Um dos professores-personagens, o Mensageiro Pi, lê o pergaminho que tem como função introduzir o contexto ficcional. Conteúdo do pergaminho:

\footnotetext{
7 Os bolsistas que vivenciaram esses papéis foram: Brenda Andrade, Samuel Gonçalves e Thainá Maria, respectivamente.

8 Ana Vitória Nogueira.
} 


\begin{abstract}
Bom dia sobreviventes.
Como vocês sabem, o mundo entrou em colapso. Agora precisamos de vocês para construir uma nova sociedade.

Estamos em 2.217 e tudo que conhecíamos e acreditávamos extinguiu-se.

Para ajudá-los, encontramos um baú que pertenceu à Capitu. Dentro dele existem dicas de como podem instaurar uma nova sociedade.

Capitu foi uma grande mulher da década de 30. Em 1930 ela previu que toda a estrutura social estaria em ruínas em um futuro não tão distante.

Ignorada por todos ao tentar alertar o que estaria por vir, Capitu construiu uma cápsula do tempo, para entrar em contato com os conselheiros.

Confiem neles!

Foram instruídos especialmente para auxiliá-los nessa nova era.

Boa sorte!
\end{abstract}

Nesse momento inicial a sala estava com suas carteiras dispostas em filas. Incorporamos essa disposição espacial para a introdução do Drama. Os moradores sentados nas cadeiras, escutaram a mensagem. Até então, eram espectadores dessa narração, mas os viajantes do tempo sabiam que essa realidade precisava ser mudada, afinal o mundo havia passado por uma devastação, que dizimou quase toda humanidade, e os que sobreviveram tinham por missão construir uma nova sociedade a partir da revisão das decisões de seus antecessores no mundo.

Os estudantes observaram atentos a narração. Como estávamos há algum tempo na escola e realizamos outras atividades teatrais, já era esperado que algo prático iria acontecer, conforme alguns adolescentes relataram posteriormente. Enquanto isso, um breve silêncio permeou o espaço após a narração. Os bolsistas olharam atentamente para os estudantes, tinham como subtexto decidir quem iriam escolher para suas equipes. Logo em seguida esse silêncio é rompido com a fala de Madame $E$ 26, que cumprimentou todos e convidou alguns moradores do Distrito para segui-la, levando consigo uma folha e uma caneta. Nesse instante os estudantes começaram a libertar seus corpos daquelas cadeiras e carteiras, rumo a outro espaço da escola. Sem saber o que iria acontecer "embarcaram" na proposta, na ficção que começou a ser tecida. Seguiram a professora-personagem, não houve resistência por parte de nenhum adolescente, o que nos levou a crer no envolvimento inicial com o processo, misturado com certa curiosidade sobre o que iria acontecer.

Na sequência o conselheiro T 22 convidou outros moradores para seguir com ele. E por último, Dr. L 22 observou os que permaneceram na sala. Os olhares estiveram atentos naquele personagem, vestido com um macacão prateado. Mais da metade dos colegas já haviam deixado o espaço. Em seguida Dr. L 22 disse "os que ficaram me acompanhem". E então rapidamente os adolescentes se levantaram de suas cadeiras e o seguiram pelo corredor da escola. Com isso, três grupos foram formados.

A imersão desse episódio deveria durar o tempo da aula, 50 minutos. Como ter uma vivência que contemplasse os sair das carteiras, deixar a sala de aula e ao final voltar para a sala? As idas e vindas demandariam quase um terço do tempo. Pensando nisso, decidimos que os percursos, tanto da ida, quanto da volta, entrariam na exploração da ficção.

As equipes iniciaram sua "navegação" pelos corredores e rampa da escola, cada uma com um percurso específico e um lugar de chegada distinto. A maioria das escolas municipais de Uberlândia possuem uma arquitetura semelhante, dois andares, 
separados por uma rampa com dois pavimentos; no centro fica o pátio, dele se pode ter uma visão de toda a escola - salas de aula e de professores, refeitórios etc. Nosso caminhar chamou a atenção daqueles que por algum motivo estavam fora das salas. Era importante para nós essa ação, de tornar visível o teatro, de mostrar que lá estávamos. Penso que trazer visibilidade nas ações que o/a professor(a) de Arte desenvolvem em seu cotidiano é uma forma de delimitar a presença do teatro na educação básica, de garantir sua existência.

\section{Uma nova sociedade}

Na continuidade desse primeiro episódio, a equipe que acompanhou a conseIheira Madame E 26 foi para o quiosque, local que geralmente utilizávamos nas aulas de teatro; a do conselheiro T 22 para um canto da escola que ficava em frente a um muro grafitado, perto da quadra de esportes; e a do Dr. L 22 atrás da cantina, em baixo da sombra de uma árvore. Com isso, ocupamos diferentes espaços da escola.

Em seus locais, os conselheiros comunicaram que Capitu deixou em sua cápsula do tempo outro pergaminho e solicitaram que um dos moradores do Distrito lesse a mensagem. E assim ocorreu, abaixo o conteúdo do pergaminho da equipe da Madame E 26:

\footnotetext{
Saudações sobreviventes!

Vejo que finalmente evoluíram o suficiente para terem acesso a minha cápsula do tempo.

Aqui estão respostas para que a civilização humana supere os últimos acontecimentos desastrosos. Usem com sabedoria.

Quem vos escreve é a grande Capitu. Nasci no ano de 1930 e fazia parte de uma organização secreta.

Nesse momento vocês terão que desenvolver os valores morais com a conselheira Madame E 26.
}

O conteúdo dos pergaminhos das três equipes era semelhante. O início igual, uma vez que tratava da apresentação de Capitu, a diferença entre eles estava nas linhas finais, que traziam a missão de cada equipe. Os integrantes do grupo do conselheiro T 22 tinham como missão criar as regras que iriam reger a economia do Distrito; a equipe do Dr. L 22 as leis, a quais população e governantes teriam que seguir; e como já dito, a equipe da Madame E 26 os valores morais. Os professores-personagens ressaltaram o fato de que os moradores eram os governantes do Distrito. Como agiriam com o poder a eles delegado pela maioria da população? Criariam leis que de fato beneficiariam a todos, e não apenas um grupo específico?

Após a leitura dos pergaminhos, os professores-personagens estimularam um debate sobre a missão de cada equipe. Nele era apontado o entendimento dos participantes sobre leis, economia ou moral. Durante os debates, os bolsistas fizeram conexões entre o passado, que seria o ano de 2.017 e o presente, 2.217. Com isso, os estudantes passaram a analisar a realidade que estavam inseridos, com um distanciamento temporal, como se seu presente fosse um passado que remetia a 200 anos atrás. 
Após o debate, os governantes elencaram os pontos que seriam transformados em leis e parâmetros para o Distrito e os anotaram em uma folha. Um dos combinados que fizemos em nossas reuniões, que os bolsistas levaram durante essa atividade, era de não influenciar as decisões dos participantes. Porém lançando questionamentos que levassem os adolescentes a perceber diversas nuances em relação aos pontos que elencavam. Os bolsistas nesse momento transitaram entre o estar presente, lançando questões provocadoras, e silenciando para que as vozes dos estudantes prevalecessem.

Com os pontos selecionados, foi solicitado que cada equipe escolhessem um porta voz. Feito isso, encaminharam para o palco que ficava no pátio, lá encontraram duas professoras-personagens, as mensageiras do tempo A 2 e A 7. Naquele momento eram as responsáveis por validar o escrito dos grupos, pois sabiam tudo o que havia acontecido no passado. Esse conhecimento possibilitava analisar se os tópicos que os moradores haviam levantado, poderiam ajudá-los, ou não, a construir uma nova sociedade, mais juta do que a anterior.

As mensageiras A2 e A7 liam em silêncio as anotações. Logo em seguida acontecia o rito da validação do escrito. Para isso, usaram uma máquina de datilografia, que estava na cápsula do tempo de Capitu. Colocaram o papel na máquina e no final datilografaram "de acordo". E com isso, os grupos encaminharam novamente para a sala de aula. Vale destacar, que havíamos combinado anteriormente que as duas professoras-personagens iriam sempre dar o "de acordo", porém como os estudantes não sabiam desse combinado, esperavam ansiosos o veredito das mensageiras.

Nossa intenção com esse momento era que os estudantes tivessem contato com um artefato de comunicação de mensagens escritas que as pessoas utilizavam antes da difusão dos computadores e dos celulares. Muitos daqueles estudantes não haviam visto uma máquina de datilografia, houve um momento de apreciação, de escutar o papel sendo colocado na máquina e o som das teclas durante o ato de datilografar.

Ao adentrarem a sala de aula, os estudantes voltaram a sentar nos seus lugares. $\mathrm{Na}$ frente, no espaço que cotidianamente é destinado aos professores, estavam os conselheiros e três moradores do Distrito, sendo um representante por equipe. Deu-se início a leitura das leis e parâmetros. Após o término desse compartilhamento, os professores-personagens anunciaram que voltariam na próxima semana. Então ao soar do sinal da escola, elemento que utilizamos como demarcador do final do primeiro episódio, os conselheiros despediram dos moradores e saíram da sala.

\section{Identidade do Distrito}

Durante a semana após o término do primeiro encontro, a equipe do subprojeto Teatro reuniu para planejar o segundo episódio. Nosso intuito era elaborar atividades que dialogassem com as já levantadas e que possibilitassem que os adolescentes fossem protagonistas do conhecimento que estava sendo tecido. Como no primeiro encontro focamos no debate e criação das leis e parâmetros da nova sociedade, nesse buscamos atividades artísticas que materializassem os tópicos levantados anteriormente. A partir disso, chegamos na seguinte proposta: elaboração da identidade 
visual do Distrito, através da criação do nome, bandeira, mapa, hino e coreografia.

No dia do segundo episódio, no início da aula, uma das bolsistas, fora do papel, relembra a turma que iríamos continuar com o processo da semana passada. Além disso, compartilhou com os adolescentes o seguinte código: quando os conselheiros entrassem na sala começaríamos o processo e os estudantes voltariam a vivenciar os papéis de governantes do Distrito.

Logo em seguida ocorreu a entrada dos professores-personagens. Para seguir o ritual da semana anterior, começamos com a fala de uma das mensageiras, no caso da $A 2$, que fez a leitura de um novo pergaminho escrito por Capitu que continha a próxima missão dos moradores: criar a identidade do Distrito. A partir de então, os conselheiros Madame E 26, Dr. L 22 e T 22 convidaram suas equipes para seguir com eles e se reunirem em um espaço da escola diferente do escolhido na semana anterior.

A equipe de Madame E 26 recebeu duas missões, criar o nome do Distrito e a bandeira. A do Dr. L 22 criar o mapa do Distrito em uma folha, logo em seguida os estudantes elaborariam imagens corporais que simbolizassem os locais criados por eles. A do conselheiro T 22 elaborar o hino e depois uma coreografia. Assim que a equipe da Madame E 26 criou o nome do Distrito uma das mensageiras, A7, comunicou para as outras duas equipes esse nome, uma vez que o incorporariam em suas criações. Os grupos utilizaram os minutos iniciais para discutir sobre o que iram fazer, a partir de então iniciaram as criações artísticas. Durante esse processo, ocorreu o revisitar de temáticas que perpassaram o debate do primeiro episódio, bem como dos tópicos compartilhados pelos grupos no final da aula anterior, uma vez que a criação da identidade visual do Distrito necessitava dos pontos elencados pelas três equipes.

Nessa atividade buscamos dialogar com algumas modalidades artísticas, que contribuíram com o processo teatral: artes visuais, através do desenho da bandeira e do mapa; música, na elaboração do hino; dança, na coreografia do hino. Para tanto, cada participante, estudantes e bolsistas, trouxeram contribuições no que mais se identificava. Aconteceu por exemplo, de algumas equipes terem adolescentes que sabiam compor música, e outros que sabiam elaborar coreografia, e então compartiIharam seus saberes com os outros colegas. Além disso aconteceu a apropriação de determinado estilo musical, o rap, com o intuito de ressignificar a ideia de hino, que os participantes cantam com seus corpos alinhados e parados. $O$ hino em forma de rap reverberou na coreografia da equipe, que assumiu o rap enquanto material criativo para os movimentos da dança.

As equipes, após concluírem as atividades, encaminharam novamente para o palco. Lá encontraram as duas mensageiras A2 e A7 que perguntaram se cumpriram a tarefa. Com a resposta afirmativa das equipes, comunicaram que na próxima semana aconteceria o compartilhar das criações. O episódio terminou com o retorno de todos para sua sala de aula. 


\section{Uma sociedade justa?}

Nesse último episódio decidimos retomar as criações do encontro anterior e alterar o ponto de vista de reflexão dos materiais elaborados, através da mudança nos papéis dos estudantes, que passariam a ser os moradores que receberiam as leis e parâmetros elaborados pelos governantes. Além disso, decidimos trazer como estímulo para o debate final, um vídeo com a imagem de Capitu, em que seria lançada a seguinte pergunta: "vocês consideram a sociedade que construíram justa?".

O terceiro e último episódio iniciou com as mensageiras do tempo A2 e A7 comunicando que as equipes iriam compartilhar entre si as criações realizadas no encontro anterior. Além disso contextualizaram alguns elementos da ficção, no caso os novos papéis dos estudantes e a viagem realizada pelos conselheiros em busca de Capitu. Logo em seguida Madame E 26, Dr. L 22 e T 22 entraram na sala de aula. Usavam figurinos inspirados em vestimentas do século $\mathrm{XVI}$, em que predominavam as cores branca, preta e azul, que diferenciavam dos tons brilhantes dos episódios anteriores. Nossa intenção era trazer novos elementos visuais que contribuíssem para a imersão dos participantes. Os mensageiros estabeleceram o seguinte diálogo:

T 22: Nós estamos um pouco perdidos pois acabamos de chegar.

Dr. L 22: Ainda estou sintonizando onde estou.

Madame E 26: Estávamos viajando no tempo procurando Capitu, que também viaja no tempo, não sei se lembram dessa história. Voltamos em 1.500 e não a encontramos, então fomos para 1.920 .

T 22: Não a encontramos, mas ela enviou um recado para nós. Vocês irão ouvir esse recado ainda hoje.

Logo em seguida os mensageiros convidaram os moradores do Distrito para os acompanharem até o quiosque da escola. Quando chegaram no local de destino, solicitaram que as equipes reunissem para preparar como iriam partilhar os materiais elaborados no encontro anterior. Assim que cumpriram essa tarefa, uma equipe por vez compartilhou sua criação, na seguinte sequência: desfile da bandeira; rap do hino e coreografia; apresentação do mapa. Em relação a esse último, vale destacar que a equipe elaborou uma estrutura que conseguiu agregar toda turma. Um representante da equipe narrou os nomes dos locais que existiam no Distrito e simultaneamente os integrantes fizeram imagens corporais que simbolizavam aqueles locais, ocupando diversos espaços do quiosque. Ao mesmo tempo, o representante convidou participantes de outras equipes para comporem as imagens corporais.

Após os compartilhamentos, o conselheiro T22 convocou todos os moradores do Distrito para ouvirem a mensagem deixada por Capitu, no caso, um vídeo que foi exibido em um tablet. Para justificar o uso de um recurso tecnológico, que não existia no ano de 1.930, elaboramos o seguinte argumento: Capitu viajava em todos os tempos e com isso tinha acesso a vários artefatos tecnológicos de comunicação, como por exemplo a máquina de datilografia e o tablet.

Nosso intuito, ao exibir o vídeo no tablet, era criar uma situação em que a turma deveria encontrar estratégias para que todos conseguissem ouvir a mensagem, uma vez que o áudio era baixo e a tela pequena, o que impossibilitaria sua assimilação por 
todos ao mesmo tempo. A turma decidiu se agrupar, uns mais próximos e outros mais distantes do aparelho, logo em seguida, pediram para que o vídeo fosse exibido novamente e trocaram os lugares, sendo que quem estava mais distante se aproximou do pequeno artefato audiovisual. A seguir a mensagem de Capitu:

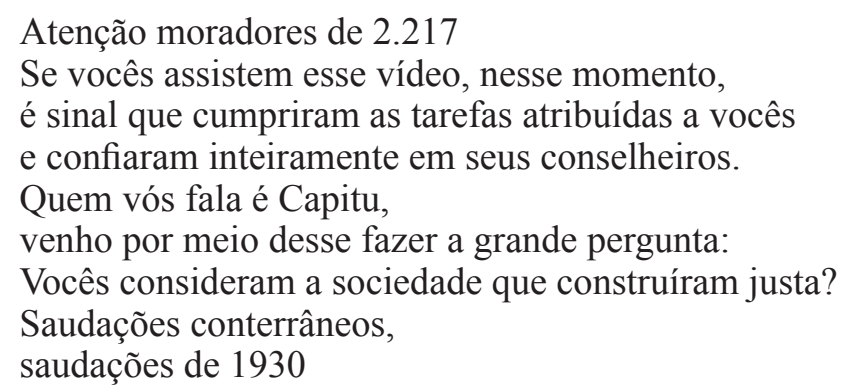

Após ouvirem a mensagem, os professores-personagens convidaram os moradores a fazerem uma roda e deram início ao debate final. Foi um momento importante para o Drama, uma vez que buscávamos o olhar dos adolescentes para os assuntos elencados por eles ao longo do processo. O debate iniciou com a leitura, por parte dos conselheiros, das leis e parâmetros construídos pelos governantes do Distrito no primeiro episódio. Logo em seguida, os moradores disseram se consideravam ou não o tópico justo para a população, com argumentos que fundamentassem suas respostas. Essa análise foi feita a partir do ponto de vista de seus novos papéis e problematizada pelos conselheiros através da seguinte questão: será que essas leis e parâmetros dialogam com os interesses e necessidades da população?

Alguns tópicos foram considerados por muitos como não sendo justos ou relevantes para a população do Distrito. Geralmente nesses momentos as opiniões daqueles adolescentes, que anteriormente haviam elaborado o tópico, transitavam entre argumentos favoráveis, mantendo com isso seu posicionamento, e argumentos contrários, criados a partir da perspectiva do papel assumido nesse último episódio.

Faltavam dois minutos para o término do encontro, nesse instante Madame E 26 encerra o debate e diz para os moradores "vocês estão com essa nova sociedade em suas mãos. Nossa missão encerra aqui. Agora é com vocês". Nesse instante os conselheiros e mensageiras se despedem da turma e o processo termina com o sinal da escola anunciando um novo horário de aula.

\section{Considerações finais}

Busquei relatar nesse artigo os caminhos que percorremos em busca de uma prática teatral que trabalhasse política e sociedade no contexto da educação básica. Para isso o método de ensino do Drama foi fundamental, pois possibilitou que os adolescentes investigassem os temas elencados enquanto pré-texto, através do contexto ficcional. Essa experiência com o Drama possibilitou que no uso dos papéis os adolescentes expressassem seus pontos de vistas durante os debates, sem o receio de serem criticados por outros colegas, uma vez que eles estavam no papel.

Os caminhos percorridos no Drama Distritos 2.217 foram tecidos processualmente. Contaram com o retorno dos estudantes e das escolhas artísticas elaboradas 
pela equipe do subprojeto Teatro PIBID. Outros percursos poderiam ser traçados a partir do pré-texto e contexto de ficção explorados, como por exemplo, atividades que possibilitassem o diálogo entre as três turmas do nono ano. Em algum momento os três Distritos poderiam ter estabelecido comunicação entre si, através de cartas, mensagens de vídeo etc. Outro ponto, seria fazer parceria com outros componentes curriculares, para aprofundar o entendimento em relação as temáticas abordadas.

Por fim, destaco a relevância do Programa Institucional de Bolsa de Iniciação à Docência (PIBID). Através dele foi possível um espaço de reflexão e prática, uma vez que contávamos com uma carga horária semanal de vinte horas, além de bolsas para os estudantes do Cursos de Licenciatura em Teatro UFU, professora supervisora e coordenador. Espaço esse que precisa ser mantido, para que outros estudantes de graduação possam desenvolver investigações pedagógicas, orientados e supervisionados por professores e professoras da educação básica e do ensino superior, e conhecer um pouco mais do ofício de ser e permanecer professor(a) de Arte em nosso país.

\section{Referências}

BOWELL, Pamela; HEAP Brian S. Planning Process Drama: enriching teaching and learning. London e New York: Routledge. 2013.

CABRAL, Beatriz. Drama como método de ensino. São Paulo: Hucitec: Edições Madacaru, 2006. (Pedagogia do Teatro)

CABRAL, Beatriz. Drama: mapeando percursos. A[L]BERTO: Revista da SP Escola de Teatro. Governo do Estado de São Paulo e Secretaria da Cultura. São Paulo, Gráfica Stampato, 6, p. 104-113, 2014.

PAULA, Wellington Menegaz de. Drama-processo e ciberespaço: o ensino do teatro em campo expandido. Florianópolis, 2016. Tese (Doutorado em Teatro) - Centro de Artes, Universidade do Estado de Santa Catarina, Florianópolis, 2016.

SIMÕES, Itamar Wagner Schiavo. Experiência e memória em processos de drama. Flo-rianópolis, 2013. Dissertação (Mestrado em Teatro) - Centro de Artes, Universidade

Recebido em: 19/08/2019

Aprovado em: 17/10/2019 